\title{
Creatividad en la enseñanza de español para negocios
}

\author{
Marta Pilar Montañez Mesas \\ Universitat de València \\ Marta.Montanez@uv.es
}

Resumen: La creatividad forma parte del aprendizaje, especialmente en ELE, también para fines específicos como español para los negocios. El proceso creativo pone orden en los nuevos conocimientos o contenidos y, al mismo tiempo, el resultado genera satisfacción en el aprendiz. En otras palabras, aprendemos mejor cuando la tarea nos interesa o nos emociona. Existen varios tipos de tareas creativas, pero podrían agruparse en dos: algunas de ellas requieren el manejo de programas informáticos y otras son de tipo retórico o literario. En las tareas que aquí se proponen, el aprendiz es el protagonista de su aprendizaje y ha de crear de la nada un texto original e inédito. Finalmente, la creatividad es útil pero tiene que adaptarse a cada grupo específico.

Palabras clave: creatividad, ELE, español para fines específicos, español para los negocios, B1-B2

\begin{abstract}
Creativity is part of learning, especially in SFL, also in Spanish for Specific Purposes like Spanish for business. Creative process put order in new knowledge or contents and, at the same time, the results make the student happy. In other words, we learn better when we are interested in the task or it produces us emotions. In general, there are two types of creativity tasks: some of them need computer programs and others are rhetorical or literary. In the tasks that are proposes here the student is the protagonist of his learning and he has to create of nothing some original and unpublished text. Finally, creativity is useful but it has been adapted to the specific group.
\end{abstract}

Key words: creativity, SFL, Spanish for Specific Purposes, Spanish for business, B1-B2 


\section{Introducción}

El objetivo de este artículo es analizar y reflexionar sobre la creatividad como fenómeno de la enseñanza de lenguas, en general, y en una modalidad de Español para fines específicos (EFE), como es el Español para los negocios, en particular.

Las destrezas a las que se orienta este trabajo son todas (expresión oral y escrita, comprensión oral y escrita e interacción), pues la creatividad puede desarrollarse en todos los usos lingüísticos y en todos los modos de la comunicación.

El nivel al que van dirigidas es, principalmente, el B2, según los estándares fijados por el MCER (Marco Común Europeo de Referencia para las lenguas).

\section{Creatividad y proceso creativo}

La creatividad, como facultad o capacidad de creación, de crear algo material o inmaterial ex nihilo, es casi exclusivamente humana y forma parte esencial de los procesos de aprendizaje de la persona, especialmente productivo en la adquisición y aprendizaje de lenguas, junto a otras cualidades innatas como la capacidad imitativa o adaptativa del ser humano.

En el momento en que pedimos una tarea creativa al aprendiz de ELE, también en enseñanza de español como L1, le estamos poniendo en la situación de "crear" un documento o discurso 'inédito', 'original', que no existe, por tanto, se convierte en un "creador" en el sentido etimológico de la palabra; casi en un demiurgo o dios que debe poner orden en el caos de conocimiento lingüístico, pragmático y cultural de la lengua meta y producir un objeto nuevo, diseñado por él mismo.

En efecto, el proceso creativo conduce de un material informe como es el lenguaje, todavía en fase de idea o pensamiento sin forma concreta, junto con los conocimientos gramaticales, léxicos y fonéticos de que dispone el alumnado, para transformarlos en un texto concreto, nuevo, irrepetible y único. El proceso creativo, concebido así, es un ejercicio de 'orden'.

caos >creación >orden

Imagen 1. Proceso creativo como orden

Al igual que en las 'creaciones' bíblicas o mitológicas, el resultado es el orden y, en última instancia, la satisfacción por haber creado algo por uno mismo. Esa satisfacción produce una suerte de 'felicidad'; y esa felicidad o satisfacción es una emoción intensa, positiva, lo que conduce a un aprendizaje más efectivo. Diversas teorías desde la neurociencia ${ }^{2}$

\footnotetext{
${ }^{1}$ Así se expresa en dos de los textos clásicos de la tradición europea:

a) “...un dios cuyo nombre ignoramos decidió poner orden en el Caos... y creó...”; (Ovidio, Las Metamorfosis, "La Creación");

b) "En el principio creó Dios los cielos y la tierra. Y la tierra estaba desordenada y vacía" (Génesis, 1).

${ }^{2}$ Un ejemplo de estas teorías se encuentra en el trabajo de Francisco Mora, Doctor en Medicina, especialista en neurociencia. Puede en la siguiente entrevista: http://www.educaciontrespuntocero.com/entrevistas/francisco-mora-el-cerebro-solo-aprende-si-hayemocion/33224.html [10-03-2017]

Desde el ámbito de la didáctica, también puede consultarse a Toro, José María (2014): Educar con "corazón”, Desclée de Brouwer.
} 
afirman que aprendemos por emociones, por tanto, aquellos saberes que se adquieren asociados a un contexto en que experimentamos una emoción positiva son más efectivos y constituyen aprendizajes a medio-largo plazo.

La idea de aprendizaje vinculada a la emoción y a la satisfacción no es nueva, ya se había expresado en los postulados del docere et delectare horaciano ("enseñar deleitando"). En efecto, las primeras enseñanzas que se asimilan cuando somos niños van ligadas al juego, a la diversión y a la vertiente lúdica del proceso. En una primera fase como imitación y, después, como 'creación', adaptando cada aprendizaje a una situación nueva, diferente. La diferencia es que mientras que imitar es simplemente 'repetir', crear es 'producir', y ese producto es el que se intenta potenciar con la creatividad, que el aprendiz no solo sea capaz de imitar estructuras en ejercicios o tareas, sino adaptar los nuevos aprendizajes a situaciones inéditas, crear otras posibilidades, aunque cometa fallos, pues lo relevante en el aprendizaje creativo no es acertar a la primera, sino experimentar con el lenguaje en tareas que le emocionen, con las que se sienta implicado, porque de ese modo aumentará su interés y el proceso será más efectivo; en definitiva, aprenderá mejor. Los errores o inadecuaciones de estilo, léxico o gramática ya se revisarán después, en otro punto del proceso, para fijar las estructuras o contenidos.

En el caso de la didáctica de ELE para fines específicos, en algunos casos la creatividad parece quedar en un segundo plano, quizá porque se asocia a este perfil de aprendices un grado de formalidad mayor que al de grupos de ELE no específicos (bien universitarios, bien adolescentes). El tipo de alumnado que asiste a EFE tiene un perfil profesional, el aprendizaje del idioma constituye un requisito para su empleo o bien una mejora en su currículum. En otros casos, son estudiantes de una titulación vinculada con el área temática de EFE que se imparte (economía y mundo empresarial, ámbito sanitario, fines jurídicos o de la administración...).

\section{Creatividad en ELE y en Español para los negocios}

En esta experiencia práctica concreta, el alumnado pertenece a EFE/Negocios. Se trata de dos grupos de unos 45-50 alumnos cada uno, vinculados a la Facultat d'Economia de la Universitat de València, matriculados oficialmente en el curso académico 2016-2017 en la materia optativa de tercer curso de Español para los negocios. Son grupos bastante heterogéneos desde distintos puntos de vista: nivel de partida en el conocimiento de la lengua meta, titulación académica, país de procedencia... La mayor dificultad se encuentra en el internivel, pues algunos apenas tienen un A2, mientras que otros se mueven con soltura en un $\mathrm{C} 1$. El nivel de exigencia idóneo para iniciar el curso debería ser un B1. Respecto de su origen geográfico, la mayoría son de procedencia europea, gracias al programa Erasmus (franceses, alemanes, italianos, ingleses, polacos...), si bien también asisten alumnos de Rusia, China y EE.UU. Por último, en cuanto a la titulación, la mayoría cursa International Business, si bien otros proceden de Turismo, ADE (Administración y Dirección de Empresas), Derecho, Ciencias Políticas, Marketing y en menor medida, de otras titulaciones, matriculados como Libre Opción (Grado en Estudios Ingleses).

Con este tipo de aprendices de español, universitarios con una orientación profesional vinculada al ámbito económico, la propuesta de realizar tareas creativas ha de adaptarse de un modo especial en consonancia con los objetivos del curso y con las expectativas de 
los estudiantes. Eso obliga a plantearse en qué sentido o de qué modo se puede enfocar la creatividad y su eficacia pedagógica.

Cuando se habla de creatividad en la enseñanza de lenguas, generalmente se asocia a dos clases distintas de tareas:

-tareas con algún tipo de soporte tecnológico, que podríamos llamar 'tareas 2.0',

-tareas artísticas, literarias o retóricas, donde se utiliza el lenguaje no solo como herramienta para comunicar unos conocimientos o ideas, sino también como un fin en sí mismo y se ejecuta la función ideativa del lenguaje (en términos de Halliday) o la función poética del modelo jakobsoniano.

Algunos ejemplos de esas tareas son los siguientes:

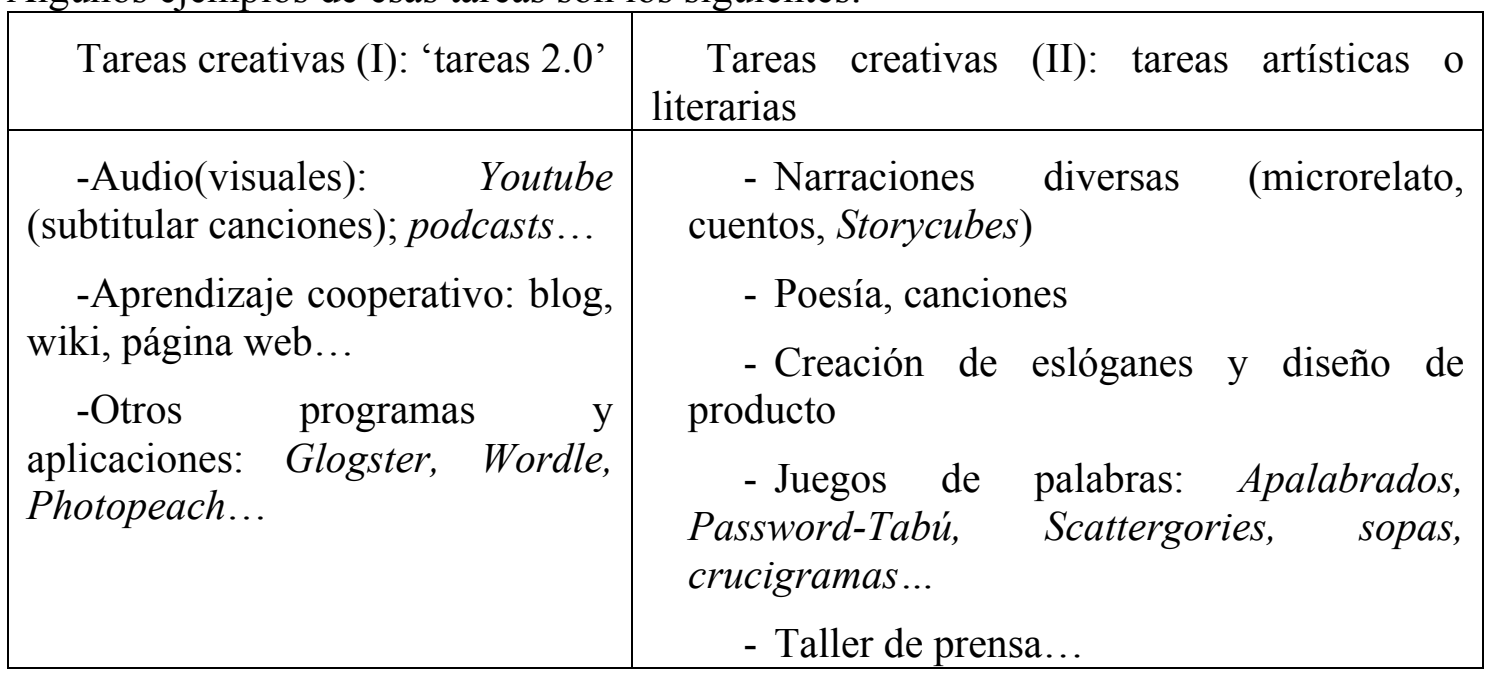

Tabla 1. Ejemplos de tareas creativas

En el caso de las tareas basadas en el uso de las TIC (Tecnologías de la Información y la Comunicación), su práctica encierra un inconveniente que muchas veces se soslaya: encomendar tareas en que el alumnado ha de manejar determinados programas presupone una competencia digital que no siempre tiene o no en el grado que requieren ciertas actividades. Por su parte, en cuanto a las tareas creativas de tipo más artístico o literario, el aprendiz de español debe activar un nivel del lenguaje que a veces tampoco tiene en su lengua materna, como el componente retórico, pragmático o una cierta competencia cultural.

Por otro lado, otra desventaja que se puede plantear es que, en algunos casos, tienen la sensación de que con estas tareas "no aprenden" y consideran que pierden el tiempo, prefieren actividades más pautadas de repetición, de comprensión oral o escrita tradicionales, o bien, de interacción, tipo role-play. En definitiva, no suelen estar acostumbrados a realizar tareas donde se potencia la creatividad, la originalidad o la expresión libre.

En efecto, en la enseñanza de ELE/N, la creatividad no está demasiado presente, pues, de alguna manera, la mayor parte de los materiales y tareas propuestos se nutren de discursos formales, técnicos o que ponen en valor, sobre todo, el léxico especializado y el uso de ciertas estructuras gramaticales formales (pasiva, condicionales...), tal es el caso de Iriarte 
(2009), Martínez y Sabater (2008) o Prada, Bovet y Marcé (2008); otros sí las incluyen, como Martí Contreras (2016).

Las tareas y contenidos desarrollados durante las sesiones de español profesional o español para los negocios, también para el turismo, el mundo empresarial o las relaciones laborales o jurídicas, suelen centrarse en la práctica de los diversos géneros textuales con los que el alumno profesional debe estar familiarizado, así como el vocabulario específico de la lengua de especialidad a la que se refiere: economía, dinero, bancos, seguros, empresa (organización, contratos, nóminas...); riesgos laborales y salud en el trabajo; entrevistas de trabajo y documentos de acceso al mundo laboral (currículum, carta de recomendación, carta de presentación o motivación...); proyectos empresariales o diseño de negocio; márquetin y publicidad...

\section{Algunos ejemplos de tareas creativas para ELE/N}

En este contexto, resultaba complejo programar actividades que fomenten ese proceso creativo y no solo la repetición de estructuras. En general, los grupos han participado de forma activa y han recibido las tareas con curiosidad y con interés, pues, en muchos casos, estaban alejadas de su práctica habitual, más centrada en la expresión escrita a partir de textos modelo.

Las tareas propuestas y realizadas en los grupos de español para los negocios mencionados, tienen como base el nivel B2 y los contenidos propios de la materia, especialmente en lo que se refiere al vocabulario específico del ámbito económicoempresarial:

a) Alfabeto de números: cada alumna/o escribe el alfabeto. Cada letra va a representar una cifra, que deben buscar. Para ello, se reparten tarjetas marcadas con una letra del alfabeto por grupos. Cada tarjeta contiene una pregunta, según el tema que interese trabajar, por ejemplo, de política y economía, cuya respuesta es una cifra:

A: año de creación de la UE;

B: edad mínima laboral en España;

C: número de ministros del gobierno actual...

Cada grupo deberá anotar las respuestas (cifras) correspondientes a cada letra y sumarlas al final, para obtener un valor numérico. El equipo que acierte más rápido ese número es el ganador. Si el alfabeto resulta muy largo, puede hacerse de forma abreviada como Semanario de números, de manera que solo han de buscar y sumar 7 datos con cifras.

Si se desea, y según el nivel del grupo, puede complicarse sugiriendo operaciones entre los valores de las letras: B multiplicado por C; el doble de A; la quinta parte de F... de manera que se trabajen todas las clases de numerales (no solo los cardinales, sino también los multiplicativos, los partitivos...) y contenidos culturales sobre economía española o europea. Esta tarea nos resultó útil puesto que gran parte del grupo no domina la expresión de los números cardinales de más de cuatro cifras, y en el ámbito económico es un contenido de tipo básico, esencial.

b) Texto con trampa: se les propone leer un texto con datos falsos sobre economía y tratar de hacer hipótesis sobre cuáles son esos datos inciertos (fechas, países, leyes...). El nivel de dificultad se logra en función de qué datos se alteren (por ejemplo: 'visita el Big Ben 
de Roma' es fácilmente detectable; mientras que en un enunciado como 'la Ley antitabaco $42 / 2010$ modifica la Ley $28 / 2006$ ' es necesario que el alumno lo compruebe buscando en Internet (la segunda ley es de 2005, no de 2006, ahí está el error), siempre serán leyes referidas al ámbito empresarial o económico, que se habrán trabajado en clase. Se activan varios contenidos gramaticales como el uso de estructuras hipotéticas, el subjuntivo, el condicional... Se realiza por parejas y después se comparte la solución con el grupo-clase. Esta actividad funcionó muy bien en uno de los dos grupos, mientras que en el otro grupo, el alumnado participó menos y tardaron más en resolver las trampas o datos erróneos.

c) Creación de 'Doodles' de empresa, en la dirección electrónica https://www.google.com/doodles. Se trata del aspecto que personaliza Google en días conmemorativos o de alguna efeméride destacada. En este caso, deben modificarlo como nombre de empresa o de un proyecto y, posteriormente, explicar en qué consiste ese proyecto o empresa. Pueden realizarlo a mano, no es necesario manejar ningún programa informático de diseño o imagen. Combina la parte gráfica (crear el Doodle de la empresa) y la oral (cuando lo exponen al grupo-clase).

d) Descripción y creación de logotipos o imágenes de marca. No se trata de demostrar grandes habilidades artísticas, simplemente, de diseñar algo sencillo y, sobre todo, explicar por qué se ha optado por esa imagen, qué representa, qué significado tiene... Una de las tareas finales del curso, propuesta por J. Martí Contreras (2016) es la creación de una franquicia. El logotipo puede referirse a esa franquicia final (como identidad visual o imagen del franquiciado, distinta al logotipo de la franquicia) o bien, a otro tipo de empresa propuesta por el docente.

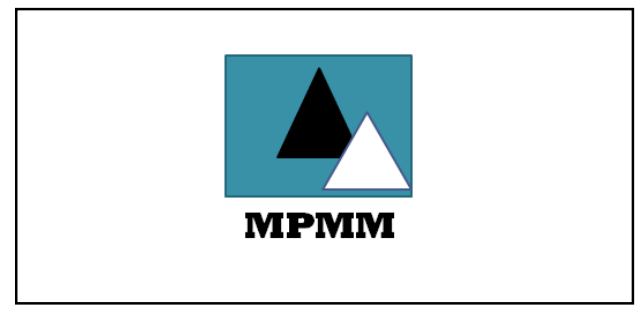

Imagen 2. Ejemplo de logotipo para franquicia

e) Creación de anuncios. Se les pidió que realizaran dos clases de anuncios publicitarios:

-gráfico: debía incluirse el logotipo y la información necesaria sobre el producto o servicio que se ofrecía. Posteriormente, debían explicar ante el grupo el significado de cada elemento y por qué habían optado por ese diseño, de modo que se potenciaran las destrezas orales. Para esta tarea, se les propusieron tres negocios:

a. una tienda para animales,

b. una tintorería a domicilio, y

c. una zapatería 'low cost'.

Aquí podemos ver una muestra de algunos de los resultados de los trabajos creativos de nuestras/os alumnas/os sobre tiendas para animales: 


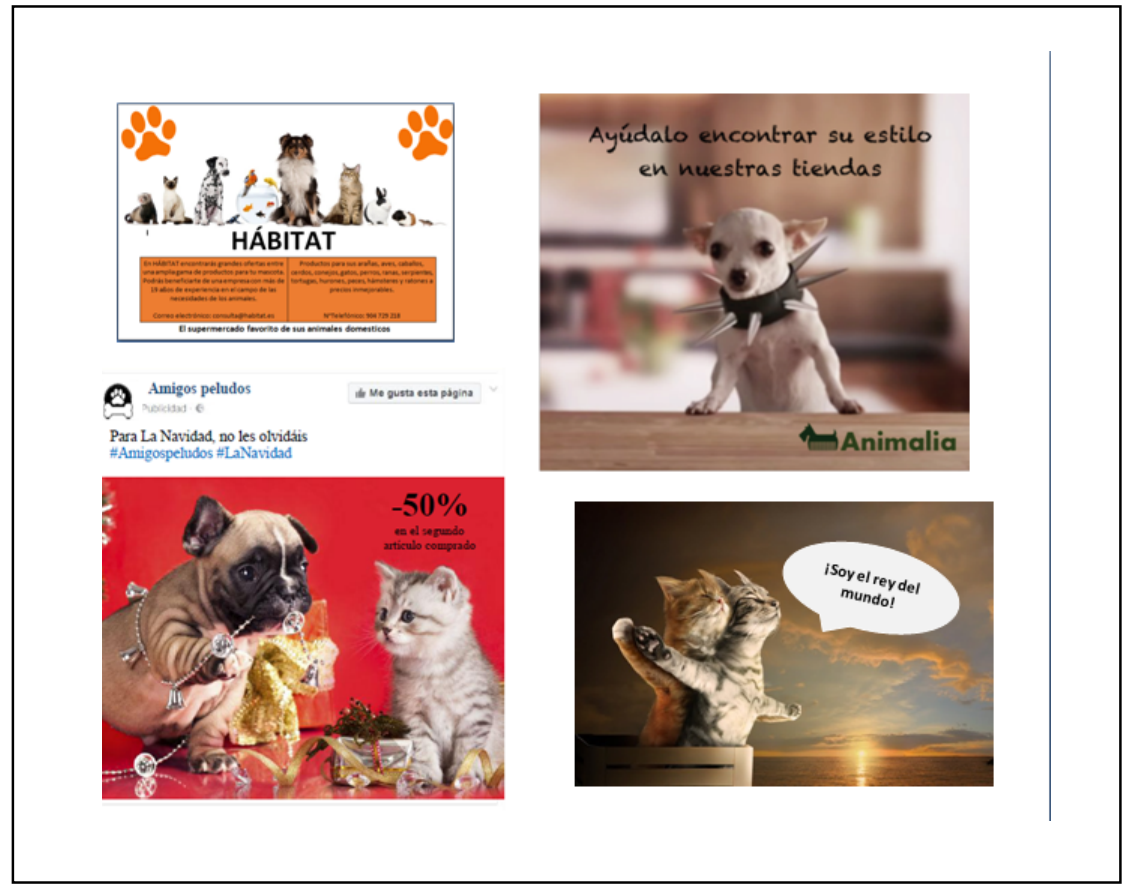

Imagen 3. Ejemplo de creación de anuncios de empresa

-guion de un anuncio audio(visual) (descripción del anuncio). En este caso, debían realizar solo el guion: música, personajes que participan, duración, medio para el que estaba destinado (radio, televisión, internet, cine). No era preciso grabarlo, solo redactar cómo sería ese anuncio. Por tanto, no necesitaban manejar programas ni aplicaciones informáticas.

f) Creación de una portada de la revista Forbes (http://forbes.es/portadas/). Con esta tarea, además de potenciar la creación libre, se pretende que el aprendiz sea el protagonista, que construya su propio futuro y se sitúe en la portada como un profesional de éxito. A partir de la portada, debe elaborar un discurso sobre cómo se ve en unos años, qué logros le gustaría obtener en su profesión y qué podría hacerle aparecer en una revista como esta. Así, pueden formular oralmente predicciones (futuro, condicional, conectores temporales...) y se trabajan varias destrezas, también las orales, porque han de explicar a la clase su portada personalizada. Se muestra una posible portada para que puedan retocarla con su imagen (no se muestra la de ningún alumno/a para preservar su identidad): 


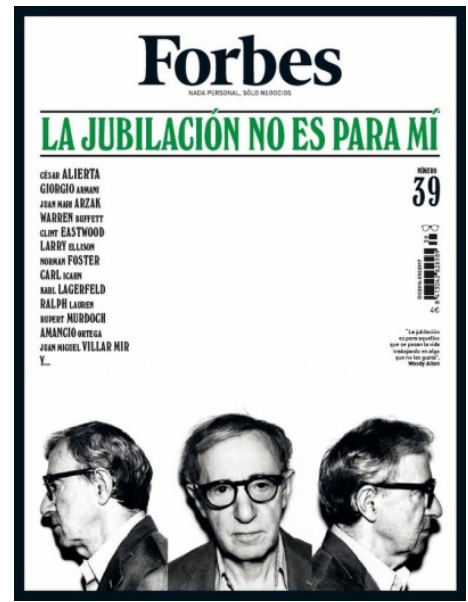

Imagen 4. Ejemplo de portada de revista para personalizarla

\section{Conclusiones}

En esta área de la enseñanza de ELE resulta menos frecuente encontrar tareas creativas o innovar en las actividades de aula, puesto que el perfil del alumnado y el tipo de contenidos impartidos parecen menos proclives a favorecer la creatividad y se orienta más a tareas formales, sujetas al ámbito de uso en que se inscribirían en el uso real y efectivo de la lengua.

Sin embargo, la creatividad aporta ventajas interesantes al proceso de enseñanzaaprendizaje que mejoran los resultados. En primer lugar, el proceso creativo ordena el pensamiento y activa diversos conocimientos, no solo implica 'repetición' sino originalidad, creación. No se trata de suprimir esas otras tareas, sino de combinarlas con otras, como las que aquí se proponen, o bien otras prácticas que añadan ese componente más imaginativo u original. En segundo lugar, este aprendizaje creativo es más eficaz, puesto que practica los contenidos propuestos en otros contextos y no solo en las estructuras de un ejercicio cerrado. Por último, crear nos produce satisfacción, felicidad, nos emociona... y la emoción fija mejor el aprendizaje.

En definitiva, como muestran estas tareas, realizadas en grupos concretos, la creatividad no está vetada en ELE/N, solo ha de ser adaptada a los objetivos, contenidos y al perfil de cada grupo.

\section{Bibliografía}

Abilleira PomAr, M. Jesús (2008-2017). A vueltas con ELE. Un blog de ELE (español lengua extranjera). Recuperado de http://www.avueltasconele.com/category/espanol-delos-negociosbusiness-spanish/

Comunidad Todo ELE (2010-2017). Foros de Español Fines Específicos. Recuperado de

http://todoelecomunidad.ning.com/group/espaolfinesespecficosturismoynegocios/forum

Instituto Cervantes (1997-2017). Centro Virtual Cervantes. Recuperado de https://cvc.cervantes.es/ensenanza/actividades_ave/ 
IRIARTE RoMero, E. y NúÑEZ PÉREZ, E. (2009). Empresa siglo XXI - Libro del alumno $+C D$, B2 y C1. Madrid: Edinumen.

MARTí CONTRERAS, J. (2016). Español para los negocios: creación de una franquicia, Valencia: Món Editorial.

MARTínez, L. y SABATER, M.L1. (2008). Socios 2. Curso de español orientado al mundo del trabajo. Libro del alumno, B1. Barcelona: Difusión.

Prada, M, Bovet, M. y Marcé, P. (2008). Entorno empresarial, Nivel B2. Madrid: Edelsa.

Toro, J.M. (2014): Educar con “co-razón”. Bilbao: Desclée de Brouwer. 